\title{
QUEM RI POR ÚLTIMO...NÃO CONHECE O CONTEXTO
}

\author{
Marta Helena Feitosa Silva \\ Instituto Federal de Educação Ciência e Tecnologia do RN- Campus Currais Novos \\ marta.silva@ifrn.edu.br
}

Artigo submetido em outubro/2011 e aceito em dezembro/2013

\section{RESUMO}

$\mathrm{O}$ presente artigo pretende relatar o desenvolvimento e os resultados do curso de extensão "QUEM RI POR ÚLTIMO....NÃO CONHECE O CONTEXTO", ministrado para professores da rede estadual de ensino do município de Currais Novos. O curso objetivou incentivar a execução de atividades de leitura e interpretação de gêneros textuais humorísticos, a saber - piadas, HQ's, tirinhas, charges e cartuns - a fim de que, em sua prática cotidiana, os professores ressaltassem a importância dos fatores de coerência, em especial, do conhecimento do contexto, entre seus alunos. O curso tomou como suporte teórico os estudos de Koch e Travaglia, acerca dos fatores que possibilitam que se estabeleça a coerência textual.

PALAVRAS-CHAVE: gêneros humorísticos, fatores de coerência, leitura, interpretação.

\section{WHO LAUGHS LAST...DO NOT KNOW THE CONTEXT}

\begin{abstract}
This paper aims to describe the development and results of the extension course "WHO LAUGHS LAST .... DO NOT KNOW THE CONTEXT", applied to state school teachers of Currais Novos city. The course aimed to encourage the implementation of reading and interpretation activities of humorous text types, namely - jokes, comics, caricatures and cartoons - so that, in their daily
\end{abstract}

practice, teachers emphasize the importance of the factors of coherence, especially the knowledge of context, among their students. The course took as theoretical support the studies from Koch and Travaglia, about the factors that make possible establish the textual coherence.

KEYWORDS: humorous text types, factors of coherence, reading, interpretation. 


\title{
QUEM RI POR ÚLTIMO...NÃO CONHECE O CONTEXTO
}

\section{INTRODUÇÃO}

\begin{abstract}
Haverá muito o que mudar, antes que o ensino de Português possa ser o que deve: um processo no qual o professor e os alunos entre si, se enriquecem reciprocamente, compartilhando sua experiência vivida de língua [...]. Mas a mudança virá daqueles que vivem o ensino, não daqueles que especulam sobre ele. De dentro. (ILARI, 1985)
\end{abstract}

É fato indiscutível que o conhecimento do contexto tem sido a porta de entrada para a construção de uma leitura de mundo eficiente. Entretanto a prática em sala de aula, nos mais diferentes níveis de ensino, leva-nos a constatar que uma parte significativa dos educandos possui uma visão superficial em relação aos acontecimentos que os cercam. Essa superficialidade traz, entre outras consequências, dificuldade de aprendizagem em várias áreas do conhecimento, notadamente naquelas que exigem familiarização com uma ampla diversidade de textos, tais como a história e a geografia, sem esquecer a própria língua portuguesa.

Essas constatações têm sido feitas a partir de atividades desenvolvidas em sala de aula, em especial com alunos do ensino médio integrado, incluindo turmas da EJA, e dos cursos subsequentes, em que se percebe a ausência de verticalização na leitura dos mais variados textos. Sabe-se que as dificuldades de leitura não se restringem à ausência de conhecimento de mundo. Essas dificuldades têm sua origem, muitas vezes, na desinformação do aluno em relação à importância da leitura, o que acarreta numa desmotivação quanto a essa prática. Por outro lado, a rejeição do aluno advém, em grande parte, de um ensino escolar que considera a leitura uma simples decodificação de símbolos em uma página impressa e a ignora como principal instrumento de discussão e de crítica entre os indivíduos.

Todas essas questões constituíram motivo de reflexões sobre possíveis formas de motivar os alunos a desenvolverem o hábito de leitura de maneira espontânea e, por que não dizer, prazerosa. Partindo do princípio de que os textos humorísticos - anedotas, charges, tirinhas, histórias em quadrinhos, entre outros - são extremamente atrativos para o aluno e exigem, dentre outros fatores, conhecimentos prévios para sua compreensão, desenvolveu-se o curso QUEM RI POR ÚLTIMO...NÃO CONHECE O CONTEXTO, direcionado a professores da rede pública estadual do município de Currais Novos/ RN. Pretendeu-se estimular os professores participantes para que, em sua prática cotidiana, promovessem atividades de leitura e interpretação desses gêneros textuais, buscando ressaltar a importância dos fatores de coerência, em especial, o conhecimento de mundo e os fatores de contextualização, entre seus alunos.

O propósito maior, certamente, foi o de contribuir para que o educando, orientado pelo professor, sinta-se estimulado a ler com eficiência, buscando compreender a realidade a fim de transformá-la, ajudando-o a tornar-se, dessa forma, um cidadão mais competente.

\section{PRESSUPOSTOS TEÓRICOS}

A linguística já tem mostrado, há tempos, a importância da utilização dos textos humorísticos na prática de sala de aula, como um elemento riquíssimo para desenvolver a habilidade de interpretação textual. Tais textos impõem uma só leitura. Se o leitor não apreende 
o efeito de humor de uma piada, pode-se dizer que ele não interpretou o texto, afirma Possenti (1988).

Travaglia (1990) também reforça a importância do humor - de uma maneira mais ampla ao apontá-lo como elemento presente em todas as áreas da vida humana, ressaltando-lhe o caráter denunciador dos instrumentos de manutenção do equilíbrio social e psicológico; revelaIhe ainda como algo que traduz uma visão de mundo diferenciada e que desmonta falsos equilíbrios.

Além dos motivos mencionados acima, a escolha desses gêneros de texto para o desenvolvimento de uma prática interpretativa encontra respaldo em Matos (2001), que a respeito das histórias em quadrinhos - apenas para citar um gênero - atribui-lhes um sem número de recursos, a saber: metáforas, onomatopeias, mensagem icônica, balões, letras de diversas espessuras, entre outros, todos relacionados aos sentimentos e ideias expressas pelas personagens. Esse mesmo gênero textual, segundo os Parâmetros Curriculares Nacionais - PCNs (BRASIL, 1998), pode desenvolver a capacidade de interpretação do leitor, devido a sua aproximação com a oralidade: o leitor consegue identificar o locutor, o locutário e o assunto de que se está falando. Sobre o humor, Beth Brait assevera:

É no humor e nos momentos de aparente descontração de uso da linguagem que vamos encontrar os mecanismos de produção de efeitos de sentido, os quais, de maneira aparentemente contraditória, mostrarão as possibilidades e as riquezas da língua. (BRAIT, 1996).

Sendo assim, não restam dúvidas de que, a despeito das vozes que ainda teimam em rejeitar esses textos, desconsiderando sua significância, eles devem, sim, ser contemplados nas salas de aula. Sua utilização, obviamente, de forma alguma substitui o estudo de outros gêneros. Os gêneros humorísticos vêm tão simplesmente somar-se aos demais numa busca, entre outros objetivos, de ampliar a capacidade de leitura reflexiva e crítica do aluno.

Escolheu-se focalizar mais especificamente os fatores de coerência por serem esses responsáveis pela legibilidade dos textos, é a coerência que estabelece o sentido nos textos. Tomaram-se como texto de referência os estudos de Koch e Travaglia (2008), que consideram a coerência como o elemento que "se constrói na interação entre os textos e seus usuários, numa situação comunicativa concreta", em decorrência dos fatores por eles elencados (p.100).

\section{METODOLOGIA E RESULTADOS}

O curso, ministrado no IFRN Campus Currais Novos, aconteceu entre 27/08/2009 e $28 / 10 / 2009$, e contou com a participação de quinze professores. Privilegiaram-se os docentes das escolas estaduais pelo fato de atuarem no ensino médio, sendo este o nível de ensino dos alunos alvo das inquietações que motivaram a realização do trabalho. Embora o objeto de estudo do curso interessasse os professores de todas as disciplinas, excetuando-se um professor de inglês, os demais participantes eram professores de Língua Portuguesa. A frequência média de participantes foi de doze a cada aula. Ocorreram dez encontros, totalizando 30h/aula.

O curso foi projetado em quatro módulos, a saber: 1ㅇ) os fatores de coerência; 2ㅇ) piadas; 3) HQ's e tirinhas; 4ㅇ) charges e cartuns. As aulas foram expositivas, com apresentação de slides no projetor multimídia e realização de atividades que foram disponibilizadas para os 
professores aplicarem em suas aulas, posteriormente. A maior parte dos textos utilizados foi coletada na Internet, em sites específicos sobre esses gêneros.

Durante o primeiro módulo, foram apresentadas algumas considerações sobre o humor, visto como um recurso bastante favorável à aprendizagem, já que os textos que lhe dão suporte utilizam variados mecanismos de produção de sentidos (metalinguagem, expressões idiomáticas, provérbios, metáforas etc.); apontam valores e controvérsias da sociedade; aguçam o raciocínio, a capacidade de ler as entrelinhas e de perceber ambiguidades e podem explicar o funcionamento da língua. Fez-se uma breve explanação dos gêneros textuais que seriam trabalhados ao longo do curso e, em seguida, foram apresentados os fatores de coerência (conhecimentos linguísticos, conhecimento de mundo, conhecimento compartilhado, inferência, contextualização, situcionalidade, informatividade, intertextualidade, focalização, intencionalidade e aceitabilidade, consistência e relevância) elencados em Koch e Travaglia (2008), e seu emprego em variados textos de humor, incluindo-se alguns textos publicitários.

O segundo módulo tratou especificamente do gênero "piada". Além de se trabalharem os fatores de coerência já mencionados, procurou-se mostrar sua importância como um gênero que reproduz com sagacidade os valores e problemas sociais, sem deixar, entretanto, de lhe ressaltar - caráter de discurso reacionário, veiculador de ideologias e reprodutor de preconceito e discriminação (POSSENTI, 2001). Foram analisadas piadas que tratavam das seguintes representações sociais: mulheres (incluindo as loiras), negros, Joãozinho (representação de "criança"), advogados, políticos, nordestinos, portugueses.

Quanto às tiras e histórias em quadrinhos, a preocupação inicial foi em desmistificar o caráter de subliteratura atribuído a esses gêneros, principalmente pela escola. Procurou-se evidenciar os aspectos positivos em se trabalhar esse gênero em sala de aula, tais como o incentivo à leitura dos signos visuais, tão presentes no cotidiano, dentro e fora da escola (mapas, ilustrações de livros, esquemas, fotografias); a melhora na percepção dos elementos da narrativa; e a possibilidade de realizar atividades transdisciplinares. Além dos fatores de coerência, foram observados, nas análises dos textos, os perfis das personagens mais encontradas nos livros didáticos de ensino médio - Calvin, Mafalda, Hagar, Garfield, Recruta Zero, Mônica, acompanhados de suas respectivas turmas ou famílias - e os elementos não verbais, o aspecto sócio-histórico e os propósitos comunicativos.

Finalizou-se o curso com o módulo "charges e cartuns". Estabelecida a diferenciação entre os dois gêneros, foram apresentadas notícias recentes àquela época e confrontadas com esses gêneros na tentativa de desenvolver, nos participantes, o processo de apreensão de sentidos: observação de marcas textuais como coerência, coesão, ironia, intencionalidade e outras. Os temas das charges e cartuns incluíam esporte, política, artes, ciência etc. - de cunho nacional e internacional - de forma a verificar o universo de conhecimento do mundo do grupo.

Ao longo do curso, várias atividades foram sendo realizadas, com o objetivo de:

1) avaliar o conhecimento prévio dos participantes sobre os assuntos que seriam tratados;

2) identificar o nível de compreensão dos participantes em relação aos gêneros estudados, observando se eles eram capazes de a) identificar o gatilho gerador do humor, b) identificar os temas abordados nos textos que poderiam ser debatidos em sala de aula, c) relacionar os textos estudados com acontecimentos da atualidade, d) identificar os argumentos subjacentes aos textos estudados; 
3) fornecer material diversificado ao que é oferecido pelos livros didáticos para serem utilizados com os alunos dos participantes em suas aulas.

Esse último objetivo procurou suprir uma lacuna deixada por muitos livros didáticos que ainda utilizam os gêneros estudados de forma insatisfatória, limitando-se a explorar - no caso específico de língua portuguesa - os conteúdos gramaticais, ignorando todo o arsenal extralinguístico possível de ser estudado. A esse respeito, os professores mostraram-se extremamente receptivos com relação ao material recebido e passaram a utilizá-los em suas aulas, simultaneamente ao andamento do curso.

O resultado das atividades realizadas pelos docentes apresentou algumas surpresas não muito satisfatórias. Seguem-se abaixo alguns percentuais recolhidos a partir das atividades aplicadas. Os resultados tomam como base a média de participantes, anteriormente mencionada: doze por aula.

89\% dos participantes afirmaram nunca ter trabalhado com os gêneros humorísticos, antes do curso, numa perspectiva diferente da oferecida pelo livro didático. Do total de participantes, $22 \%$ sequer utilizavam o gênero em suas aulas.

Alguns dos fatores de coerência estudados, tais como a focalização, a inferência e o conhecimento compartilhado eram desconhecidos como sendo "fatores de coerência" por cerca de $60 \%$ dos participantes. Dado esse desconhecimento, tornava-se difícil também reconhecê-los nos textos, nas atividades orais ou escritas. Em virtude dessas dificuldades, algumas atividades, inicialmente elaboradas para serem executadas individualmente, foram aplicadas em duplas ou em grupos de três integrantes, para que pudesse haver um compartilhamento de informações.

No que diz respeito aos personagens de HQ's e tirinhas, o Recruta Zero foi o menos identificado pelo grupo. Os demais foram identificados, embora nem sempre houvesse conhecimento satisfatório de seus perfis, como foi o caso de Mônica, Cebolinha e Magali, da Turma da Mônica. O mesmo ocorreu com a mulher de Hagar, Helga. O perfil de Calvin e de Mafalda - personagens constantes dos livros utilizados na escola - não chegava a ser bem compreendido por aproximadamente $50 \%$ do grupo, o que certamente comprometeu, inicialmente, a compreensão das histórias analisadas. O módulo sobre as tiras e HQ's foi considerado pelos participantes o que melhor contribuição trouxe à sua prática profissional, conforme atestam os seguintes depoimentos:

ALUNO 1

[...] as tirinhas e as histórias em quadrinhos, cada um em sua particularidade torna os atores mais críticos diante das situações, os vícios de linguagem e todo um conteúdo arraigado nas entrelinhas dos pequenos comentários.

ALUNO 2

Todos eles, mas especialmente as tirinhas, pois às vezes ficava obscuro algum detalhe que, por exemplo, por não ter conhecimento prévio do perfil dos personagens, tornava-se mais difícil ou vago o conteúdo da tira.

ALUNO 3 
As histórias em quadrinhos. Talvez pelo fato de ter sido alfabetizada pelas histórias em quadrinhos, eu senti prazer em descobrir novas maneiras de trabalhar esse gênero.

De um modo geral, a leitura e a interpretação dos textos apresentados nos slides e nas atividades foram satisfatórias. $25 \%$ dos participantes, entretanto, sentiam dificuldades reais de compreender os textos. Esse índice foi detectado, principalmente, na realização de atividades de interpretação de piadas, charges e cartuns.

Nas atividades que confrontavam as charges com os fatos noticiosos que as originaram, registrou-se um percentual elevado de desconhecimento do fato jornalístico (46\%), ocasionado, segundo os depoimentos recolhidos, pela falta de tempo disponível para acompanhar os noticiários televisivos e impressos. Pôde-se observar que $70 \%$ do grupo apresentou bom desenvolvimento de competências de uso da linguagem oral e escrita. Cerca de $90 \%$ mostraramse bastante participativos e dispostos a realizar as atividades propostas.

$\mathrm{Na}$ avaliação dos professores, o curso foi bastante positivo. Todos registraram que o curso lhes proporcionou um novo olhar sobre os gêneros humorísticos, principalmente sobre as múltiplas possibilidades de sua utilização junto aos alunos. Reconheceram também a necessidade de ampliar sua visão de mundo, não apenas através da leitura exigida no seu dia a dia, para a prática escolar, mas também e, principalmente, através de uma observação atenta de tudo o que os cerca, verificando como o conhecimento do contexto colabora na construção de diferentes saberes. Propuseram-se a utilizar esses gêneros textuais com mais frequência em suas aulas, dando ênfase aos aspectos trabalhados durante o curso.

Quanto aos aspectos negativos, o grupo apontou a pequena quantidade de participantes como uma das falhas, o que segundo eles, impossibilitou uma ampliação das discussões sobre os temas abordados. Também houve queixas quanto ao horário (turno vespertino), já que, para alguns, tornava-se difícil o comparecimento por causa do trabalho. Outros julgaram que o tempo de duração da aula deveria ser reduzido, para um melhor aproveitamento dos participantes.

Para averiguar se o curso provocou o interesse do grupo em adotar uma nova prática na utilização dos gêneros humorísticos foi feita a seguinte pergunta: "O que mudou ou poderá mudar em suas aulas, ao utilizar textos humorísticos após o curso?"

ALUNO 2

Antes de iniciar qualquer atividade com esses gêneros, agora tenho mais capacidade de apresentar os personagens, suas características e acrescentar informações que ajudarão na interpretação.

ALUNO 4

A forma de abordar alguns gêneros, tendo em vista que o curso me proporcionou um conhecimento mais aprofundado sobre os textos e também apresentou formas significativas de trabalhá-los.

ALUNO 5

O curso me ajudou a enxergar as várias possibilidades de ver um texto humorístico e levar meu aluno a desvendar esse tipo de texto. 
De modo geral, as expectativas do grupo foram alcançadas. Os participantes gostaram da metodologia utilizada, julgaram relevantes os conhecimentos adquiridos, principalmente no tocante às alternativas sugeridas para se trabalhar com os gêneros estudados. Segundo eles, a visão sobre os gêneros humorísticos foi ampliada e as possibilidades de trabalho sugeridas constituíram-se ótimas ferramentas em sua prática pedagógica.

\section{CONSIDERAÇÕES FINAIS}

O trabalho desenvolvido com os professores em Currais Novos suscita algumas reflexões. Primeiramente verificou-se a grande dificuldade em agregar um grupo significativo para participar do curso. Parte dessa dificuldade foi atribuída à impossibilidade de os professores serem liberados de suas atividades para a participação de eventos, ainda que se trate de uma capacitação que gerará benefícios para o educando e, consequentemente, para a escola como um todo. Um dos participantes, inclusive, chegou a sugerir que o IFRN solicitasse a disponibilidade dos professores para participarem do curso. Alguns dos participantes consideraram que houve pouca divulgação, apesar de todas as escolas estaduais do município terem sido visitadas e de terem sido distribuídos panfletos e cartazes para serem afixados nos murais. Mas não se descarta, também, certo desinteresse pelo curso, motivado, talvez, pelo desconhecimento da sua abrangência transdisciplinar.

Um dado gratificante foi a ótima receptividade dos professores em relação ao curso. A maioria dos participantes envolveu-se com as aulas participando dos debates, realizando as atividades, contribuindo, dessa forma, para a dinamicidade dos encontros. Ainda que o número de participantes não tenha correspondido às expectativas, essa resposta positiva mostrou o quanto é importante proporcionar aos educadores eventos de capacitação. Muitos inclusive solicitaram que houvesse posteriormente a "continuidade" do curso, como uma forma de aprofundamento dos assuntos tratados.

No que diz respeito ao conteúdo abordado, especificamente, constatou-se que uma parcela significativa dos professores restringia a utilização dos gêneros textuais humorísticos ao que é sugerido por grande parte dos livros didáticos. Esses manuais, desconsiderando as diretrizes dos PCN's, ainda os tratam como gêneros de menor importância, muitas vezes apenas como suporte para desenvolver conteúdos gramaticais. Perde-se, assim, a oportunidade de explorar com eficácia a estrutura, as marcas linguístico-discursivas e semióticas desses gêneros, ficando esses esvaziados de sua função. Essa má utilização se reflete, naturalmente, na dificuldade de compreensão leitora dos alunos em relação a esses textos. Essa lacuna poderia ser suprida, pelo menos em parte, caso os livros didáticos trouxessem sugestões de atividades relacionadas a esses gêneros que explorassem adequadamente seus recursos. Já há sinais de avanço nesse quadro, é certo, mas ainda há o que se discutir e melhorar. E essa é uma discussão que não cabe aqui, por ora.

Outro dado, certamente o mais preocupante, é o fato de alguns docentes não conseguirem estabelecer nexos durante a leitura de alguns textos, por causa do desconhecimento de alguns fatores de coerência, em especial o conhecimento de mundo e a dificuldade de inferir informações ou de contextualizar algumas situações nos gêneros estudados. Tendo em vista que, ao iniciar-se o curso, partira-se do pressuposto de que os profissionais já teriam certo cabedal de conhecimento nesse sentido, esse dado surpreendeu. Por outro lado, essa realidade explica, pelo menos em parte, a dificuldade dos alunos em fazer a 
leitura desses gêneros. De que maneira poderá o professor auxiliar os alunos a vencerem suas dificuldades, estimulando-os a uma prática leitora que extrapole os muros da escola, se ele mesmo não está, em alguns casos, apto a fazê-lo?

É claro que o grupo observado - 12 participantes - não representa um universo significativo. Entretanto o dado não pode ser desconsiderado. A competência exigida nesse caso deve valer para todos os educadores, sem exceção, pois todos atuam e todos são corresponsáveis - juntamente com os condicionantes culturais, sociais, políticos e econômicos pelo processo da construção de saberes dos alunos. Caberia, então, aos poderes públicos, em todas as esferas, investir maciçamente na capacitação desses profissionais, e não apenas estimular, mas exigir sua participação em cursos, minicursos, palestras, quaisquer eventos que promovam esse fim. Infelizmente não é essa a realidade que se tem vivenciado, conforme se verificou no depoimento dos professores.

Como a cada um cabe o seu papel, o curso ofertado pelo IFRN/ Campus Currais Novos possibilitou aos profissionais que participaram deste evento dar um passo à frente na consolidação de sua carreira. Espera-se que a esse, sigam-se outros.

\section{REFERÊNCIAS BIBLIOGRÁFICAS}

1. BRAIT, B. Ironia em Perspectiva Polifônica. Campinas: UNICAMP, 1996.

2. BRASIL. Secretaria de Educação Fundamental. Parâmetros curriculares nacionais: terceiro e quarto ciclos do ensino fundamental: introdução aos parâmetros curriculares nacionais. Brasília: MEC/SEF, 1998.

3. ILARI, R. A Linguística e o ensino da língua portuguesa. São Paulo: Martins Fontes, 1985.

4. KOCH, Ingedore et TRAVAGLIA, Luiz Carlos. A coerência textual. 17. ed. São Paulo: Contexto, 2008.

5. MATOS, Magda Diniz. Na trilha do texto: atividades sociointeracionistas em língua portuguesa. São Paulo: Quinteto Editorial, 2001. (Coleção na trilha do texto).

6. POSSENTI, Sírio. A imposição da leitura pelo texto: casos de humor. Caderno de Estudos Linguísticos, n.15, p. 111-116, jul./dez. 1988.

7. . Análise do discurso: Piadas são relevantes em estudos do funcionamento da linguagem. Ciência hoje. Vol.30, no 176, p. 72 - 74. 2001.

http://aescritanasentrelinhas.d3estudio.com.br/wp-content/uploads/2009/02/o-humor-e-alingua-texto.pdf, acesso em 15/06/2009.

8. TRAVAGLIA, L. C. Uma introdução ao estudo do humor pela linguística. D.E.L.T.A., v. 6, n. 1, 1990. 